\title{
ARTIFICIAL EMPHYSEMA IN THE DIAGNOSIS OF SURGICAL CONDITIONS OF THE TRUNK
}

\author{
R. Brearley, Ch.M., F.R.C.S. \\ Lecturer in Surgery, University of Liverpool
}

From the Surgical Clinic, University of Padua (Director, Prof. V. Pettinari) and the Institute of Surgical Pathology University of Padua (former Director, Prof. V. Pettinari)

RADIOLOGICAL delineation of soft-tissue structures by gas in the areolar planes of the trunk is a wellknown incidental finding in cases of traumatic surgical emphysema. The phenomenon was first put to practical use by Carelli (Carelli, rg2 ra and b; Carelli and Sordelli, I92 I) and by Rosenstein (Rosenstein, 192I) who independently reported outlining the kidney by the insufflation of gas through a needle puncture in the loin. Although useful information is obtainable in this way, the method did not gain general acceptance because of the danger of fatal gas embolism following accidental puncture of the kidney itself, a vascular tumour, or one of the numerous veins (renal, lumbar, vertebral, caval, etc.), adjacent to the perinephric space. Deaths from these causes were, in fact, reported. A further shortcoming is that examination of both kidneys calls for bilateral puncture. These disadvantages are principally determined by the site of injection and it is evident that they could be largely eliminated by introducing the gas through some other portal into an avascular part of the deep areolar tissue and inducing it subsequently to migrate to the target.

The first extensive and systematic study of the diffusion of artificially introduced gas in the deep areolar planes of the trunk in man was carried out by Ciarla (I94ra and b). In a series of experiments dating from I 936 , he injected both cadavers and living subjects with varying quantities of air or oxygen, which he introduced into the epidural space by puncture either of the sacro-coccygeal membrane or of the ligamenta flava in the lumbar, dorsal, or cervical regions. By subsequent X-ray examination of the living subjects and dissection of the cadavers, he was able to show that the gas diffused throughout the muscles of the loin, the subserous areolar spaces of the abdomen and pelvis, the mediastinum, and the neck. Gas also entered the roots of the limbs and could travel as far as the popliteal fossa, but it did not reach the gut or the omentum although the mesenteries weres filled and the duodenum lifted off the posterior abdominal wall by gas surrounding the pancreas $\vec{N}$

Similar results were demonstrated in the $\operatorname{dog}_{5}$ by Baccaglini (r948, a and b), using a lumbar para-vertebral approach. Fluoroscopy showed that the injected gas could be induced by changesw of posture to drift about the deep areolar planes as though it were a collection of free bubbles in a viscous fluid medium, passing from the reto peritoneal spaces to the mediastinum and neck a d outlining the contained structures. In this wo he later evolved a technique for obtaining medi astinal pneumograms (Baccaglini, 1949, 1950)

General interest in pneumography was re-\# awakened after the description by Ruiz-Rivas (1947, I948), of the technique of peri-rena 5 pneumography by the pre-sacral route, which hes had evolved after first using the extra-duraf method (though evidently unaware of Ciarla's earlier work). Descriptions of the pre-sacrats method were published in America in $195 \%$. (Ruiz-Rivas, 1950) and in Britain in 1951 (Black윽 wood, I95I) and 1953 (Tinckler, 1953). In the ensuing decade, this form of investigation has? become widely used in Italy and South America and favourable reports have also appeared in France, Germany, Hungary, Russia and Switzer $\frac{D}{8}$ land. In America, a more cautious attitude has? been adopted, and Ransom, Landes and McLelland (1956), who carried out a postal survey reported that opinion was sharply divided with respect to the value and hazards of the investiga $-\omega$ tion. The 1,267 urologists who replied to the questionnaire reported 58 fatal and 64 non-fatae gas emboli in the course of over 11,000 examinations. Some of these resulted from the use of the loin route, but pre-sacral insufflation was not immune from occasional fatal consequences $\underset{\mathbb{\circ}}{\stackrel{\circ}{ }}$ 
though it seemed to be a safer method. In Britain, following Blackwood's paper, limited use has been made of pre-sacral insufflation, particularly in the investigation of suprarenal tumours, for which purpose there may sometimes be no effective alternative. Recently, Davidson, Havard and Bodley-Scott have reported the demonstration of enlarged retroperitoneal lymph nodes by the same method (Davidson, Havard and BodleyScott, 1959).

At the University of Padua, in the Radiological Departments of the University Surgical Clinic and Institute of Surgical Pathology (under the direction of Prof. V. Pettinari), pre-sacral insufflation has been in frequent use since 1949 and it has yielded much useful information about the site, extent and nature of a variety of conditions affecting the soft structures of the pelvis, abdomen, mediastinum and neck, much of which could not have been obtained in other ways. The present communication is based upon a review carried out in the autumn of 1959 of the records of the latter Institute, together with a personal study of a series of patients investigated there, and from November, 1959, onwards, in the University Surgical Clinic. In illustrating the applications of the method, it is impossible to treat the subject in an exhaustive manner and the examples shown constitute only a sample selection. A fuller account of the experience of the two departments up to I953 has already been published in the form of a monograph (Bonomini and Baccaglini, 1953).

\section{Method, Side Effects and Complications}

Over I,000 patients have now been investigated in each institution without mortality and without recognizable evidence of gas embolism. In view of the fatalities reported elsewhere, it therefore seems desirable to consider with some minuteness the details of the technique adopted, as it is presumably the manner of introducing the gas which determines the possibility of intravenous injection.

\section{Apparatus}

A stiff, curved needle with a short bevel and a well-fitting obturator is used. Several sizes are available from $7 \mathrm{~cm}$. to $1 \mathrm{I} \mathrm{cm}$. in length. The external diameter is $\mathrm{I} \mathrm{mm}$., the radius of curvature is II cm. and the hub has a Record fitting with a bayonet lock. In use this is connected to an indifferent length of rubber tubing leading to one of the ports of a three-way tap which forms the nozzle of a $250 \mathrm{cc}$. calibrated glass syringe. The second port of the tap is connected to an oxygen cylinder, while the third port communicates integrally with the barrel of the syringe. The plunger is of metal and carries a thumb ring. The cap, also of metal, has two finger rings to allow easy one-handed operation. Formerly, the tubing between syringe and needle was fitted with a $\mathrm{T}$-connection communicating with a water manometer. This is an added safety measure, and except in the hands of a very experienced operator, it is better to include it.

\section{Technique of Puncture}

The patient is placed in the knee-elbow position. In most cases, it is convenient to introduce the needle at one or other side of the coccyx but if the coccyx is short and forward flexion is slight, the infra-coccygeal, post-anal route is equally suitable. Formerly, the operator's left index finger was introduced into the patient's rectum, but this has now been discontinued. Although giving an indication of the position of the needle, this practice carries at least the possibility of impaling the rectal wall on the needle tip and so promoting either portal venous gas embolism or interstitial emphysema of the gut wall, with subsequent necrosis and perforation. After introduction of the needle, trial aspiration is performed with a separate small syringe. The $250 \mathrm{cc}$. syringe is then filled from the oxygen cylinder and the needle connected to the appropriate tube.

\section{Technique of Injection and Diffusion}

Two principles govern the introduction of the gas. Firstly, the rate of injection should be slow, the pressure used never exceeding $30 \mathrm{~cm}$. of water: ordinarily it should be nearer to $20 \mathrm{~cm}$. (Bonomini and Baccaglini, r953). The patient should feel no pain; if this arises, it indicates toorapid injection. Secondly, the quantity of gas injected should be sufficient to outline the structure under investigation and should not exceed that amount. Two syringe-fulls of oxygen (500 cc.) are therefore injected slowly and the patient with the needle still in situ is then placed in an appropriate position while the diffusion of the gas towards its target is followed by fluoroscopy. Further small quantities are injected as may seem necessary and when adequate contrast is observed in the desired region, the needle is withdrawn. Success depends upon judging correctly how much gas to use. With too little, the outlines do not appear but with too much they become obscured again and it is often profitable to study extensive regions or organs (such as the renal fossæ, subphrenic spaces or liver) by examining a part at a time, using a limited quantity of gas and inducing it to drift from place to place by appropriate changes of posture. In the interests both of safety and satisfactory results, it can not be too strongly emphasized that the principle of the method is not to inflate the patient with a large pre-determined volume of gas, but to outline 
selectively a chosen part by causing a modest but sufficient quantity to diffuse towards it. The target is then studied by plain films and tomograms in both planes. Occasionally counter contrast is added in the form of barium swallow, intra-venous pyelography, aortography, or other appropriate means.

\section{Positioning of the Patient}

Owing to the attachment of the retro-peritoneal fascial planes about the great vessels, it is impossible to induce gas to pass from one side to the other once it has risen above the pelvic brim. It is therefore important to ensure that the position of the patient is regulated in the early stages of the insufflation in such a way as to direct the gas to the locality in which it is desired. A semi-prone position with slight head-up tilt directs the gas towards the renal fossa of the uppermost side, giving good visualization of the renal and adrenal outlines. Increasing the head-up tilt until the patient is almost vertical, while turning forward from the prone position, brings the gas fully into the upper abdomen where it outlines the lateral border of the spleen on the left, or the lateral and lower borders of the liver, and sometimes the gall bladder, on the right. If a slightly head-up supine position is maintained, the gas passes up the midabdomen to surround the great vessels, pancreas, pillars of the diaphragm and the medial aspects of the spleen and liver. Aided by further head-up tilt and a few deep inspirations, it then enters the mediastinum where it can be directed mainly to the anterior part by leaning the chest backwards, or mainly to the posterior part by adopting the reverse position. Ultimately, if the patient maintains the erect posture, it reaches the neck where it may be detected by palpation.

\section{Complications and Side Effects: Precautions Gas Embolism}

This is the most feared complication. So long as air or oxygen are used, it is wrong to pretend that this danger can ever completely be eliminated, since the same peril exists even with intracavitary air injection (air urethroscopy, uterine insufflation) in which there is no possibility of pricking a vein. Nevertheless, the performance of over 2,000 examinations without incident suggests that with proper technique, a fair degree of safety can be attained, within the limits of tolerability for an examination which will yield information not otherwise obtainable, and comparable with that of many other generally accepted diagnostic procedures which carry a small risk.

Besides the scrupulous observance of all the points of technique described above, particularly slow injection at low pressure, a number of other safety precautions have been suggested. Blackwood (195 I) advised the use of a small (20 cc.) syringe with repeated trial aspirations. In my own $\frac{2}{z}$ experience, this is inconvenient and the repeated $\frac{\$}{8}$ manipulation of the syringe and three-way tap $c$ usually displaces the needle somewhat during the course of the injection. Zinsser (1954), and $\stackrel{5}{\rightarrow}$ Landes and Ransom (1957) suggest introducing a 음 fine polythene tube through a needle which is then 흠 withdrawn. A polythene tube is much less likely $\frac{\sigma}{\sigma}$

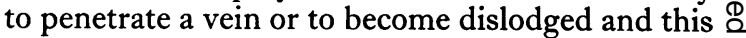
method makes insufflation in the erect posture very convenient. It is important to carry out trial $\vec{\circ}$ aspiration before introducing the polythene tube as well as after, as it is known that (using a needle), $\vec{\omega}$ air embolism can follow a bloody tap even if the needle is withdrawn and re-introduced (Ransom, 8 Landes and McLelland, 1956). Presumably the support of surrounding structures can hold open $\underset{v}{\omega}$ the puncture in the vein wall, allowing air to enter. $\vec{N}$ Zinsser (1954) and Davidson et al. (1959), advised or the injection of 5 to ro cc. of fluid (procaine or $\vec{N}$ normal saline) before insufflating. This starts off $ᄋ$ the separation of the rectum from the sacrum in a $\frac{}{5}$ safe way and subsequently, with a finger in the $\vec{r}$ rectum it is possible to feel the entering gas bubbling through the pool of fluid. A further $\frac{\widehat{\alpha}}{\sigma}$ possible combination of refinements would be to $\vec{\theta}$ introduce a polythene catheter, followed, after trif aspiration, by injection of a small quantity of nons. irritating contrast medium under fluoroscopic ane radiographic control. This would demonstrate the position of the catheter tip, while the possi- o bility of intravenous injection would be revealed by the appearance of a phlebogram which could $\stackrel{\perp}{\circ}$ be easily recognized.

It has also been suggested that gas embolism may occur during insufflation, even after a dry puncture, as a result of tearing of veins as the gas separates the tissue planes. This seems very improbable however. Certainly, in cases of 3 slowly developing traumatic emphysema following injuries to the respiratory tract, fatal air embolism is not seen, even though the interstitial emphysema may be great, and under considerable tension. In those cases in which fatal embolism has occurred during the later stages of a diagnostic insufflation, $\frac{D}{O}$ it seems more likely that it has resulted from displacement of the needle tip. Certainly, in the case $N$ reported by Ransom et al. (1956), the needle had actually been removed and re-introduced. The $N$ claim of these authors that in two fatal cases, air $\underset{\omega}{ }$ was demonstrated entering a torn vein at a distance from the injection site, seems to be out of keeping with everyday experience of the limitations of $\Phi$ autopsy technique.

It is usually considered that the injection of ${ }^{\circ}$ oxygen carries less risk than the injection of air, 
but Ransom et al. (1956), concluded from their survey that it was not so. The experiments of Harkins and Harmon (1934), further bear this out. Carelli (r92ra and b), recommended carbon dioxide in preference to oxygen because of the much shorter duration of the local discomfort associated with its use and Landes and Ransom (1957) strongly advise it on grounds of safety. Besides claiming that it is 20 times more soluble than oxygen, ${ }^{*}$ they quote a considerable body of clinical and experimental evidence showing it to be relatively innocuous even when injected directly into main vessels.

Davidson et al. (1959), who tried it, found it to be unsatisfactory because of rapid absorption. Landes and Ransom also encountered this difficulty but were able to obtain satisfactory nephrograms by introducing the gas in somewhat larger volumes with the patient in the erect position. They also advance convincing arguments for the belief that the erect posture increases the safety of the method. Other gases have also been proposed, including nitrous oxide and helium but such proposals are not based upon experiment. Helium, in fact is notably insoluble.

Injection with the patient in the left lateral position has also been recommended as a precaution against fatal gas embolism. While there

* They do not say in what fluid or under what conditions of temperature or pressure. The only relevant consideration would be in relation to mixed venous blood, since to avoid embolism the gas would have to disappear during transit through the inferior vena cava and right heart. In three specimens of mixed venous blood kindly examined for me by Dr. J. S. Robinson, of the Department of Anæsthesia, University of Liverpool, the following results were obtained:

Contents of gases in mixed venous blood in $\mathrm{ml} . / 100 \mathrm{ml}$. of blood

Hb. of all specimens $98 \%$ or over Ambient barometric pressure $758 \mathrm{~mm}$. $\mathrm{Hg}$.

Freshly withdrawn

$\begin{array}{cc}\begin{array}{c}\text { Carbon } \\ \text { dioxide } \\ 54.5\end{array} & \begin{array}{c}\text { Oxygen } \\ 18.5\end{array} \\ 206.4 & 25.5 \\ 151.9 & 7.0\end{array}$

After equilibration with $100 \%$ pure

gas $\ldots$ atential capacity to absorb pure

gas

. . . . . .

$7 \cdot 0$

Notes

I. Landes and Ransom speak of 'solubility', though other factors also contribute significantly to the uptake of these gases.

2. The normal figure quoted for $\mathrm{CO}_{2}$ capacity of whole blood ( 43 to $56 \mathrm{ml}$./100 ml. blood) is, of course, the $\mathrm{CO}_{2}$ content of blood in equilibrium with alveolar air $\left(\mathrm{PCO}_{2}=40 \mathrm{~mm}\right.$. $\mathrm{Hg}$. $)$, not pure gas.

3. At normal rates of cardiac output (and intake) of 4 1. per minute (=66 ml./sec.), these figures would indicate that, granted adequate mixing, approximately $100 \mathrm{ml} . \mathrm{CO}_{2}$ could be absorbed per second, a figure far exceeding any likely rate of introduction.

4. In fact, when the $\mathrm{CO}_{2}$ content reaches $206.4 \mathrm{ml}$./ 100 $\mathrm{ml}$., the blood $\mathrm{pH}$ is reduced to 6.64 , a level likely to prove fatal of itself. is no doubt that assumption of this posture is a valuable first-aid measure (it was thought to have been life-saving in five of the non-fatal cases reported by Ransom $e t$ al.), it is not completely proof against massive embolism; indeed, two of the fatal cases in that series died on the left side.

\section{Sepsis}

Accidental introduction of the needle into the rectum has been reported, with consequent ischio-rectal suppuration. With due care, such mis-placement should be rare. It has occurred once or twice in the present series but has not been followed by detectable sepsis. In these cases, the needle was withdrawn completely and the examination temporarily abandoned. After several days without evidence of local or systemic disturbance, insufflation was performed at a second sitting.

\section{Hypotension}

As the gas ascends through the retro-peritoneal spaces, there is usually a fall of systolic blood pressure of about $20 \mathrm{~mm}$. $\mathrm{Hg}$. This is symptomless unless the patient's normal systolic pressure is below I IO mm. of mercury. In such a case, it is advisable to inject a pressor agent before the examination. Other physiological and paraphysiological effects described include bradycardia, elevation of venous pressure in the upper limbs, delayed renal excretion of indigo-carmine, and transient disappearance of symptoms in cases of Buerger's disease. The tone and movements of the gastro-intestinal tract seem to be unaffected, at any rate in adults, though hypotonia of the small gut has been reported in children.

\section{Discomfort}

Although pain should be completely absent during the injection, patients are usually aware of the approximate position of the gas, which gives rise to a sensation of fullness. Sometimes, as it enters the perinephric space, which it does in the region of the hilum, there is a transient stab of pain in the flank. A similar pain, also of short duration, is sometimes felt when gas enters the extra-pleural areolar tissues of the thoracic wall, which it often does after outlining the right sub-phrenic spaces. After examination of the mediastinum, gas ascending into the neck may infiltrate the larynx, causing transient hoarseness, while pre-vertebral, retropharyngeal gas may produce subjective dysphagia. Apart from these discomforts, the examination is remarkably free from unpleasant side-effects, and is often carried out upon out-patients.

In summary, adherence to the main points in the technique outlined above is known to combine good contrast with tolerable safety. The important points seem to be the slow introduction of modest 
amounts of gas at low pressure and preferably under manometric control starting in the kneechest position and subsequently regulating the diffusion of the gas by postural means, under fluoroscopic control. The use of carbon dioxide although attractive on grounds of safety has not been shown to be satisfactory for examinations other than nephrography and in view of the difficulty encountered even here, might well prove inadequate for outlining the structures of the mediastinum.

\section{Possibilities and Scope: Clinical Experiences}

Because of the ease with which the gas may be directed to any part of the deep areolar planes of the trunk, it is possible to outline virtually every structure in or adjacent to the pelvic and abdominal parietes, mediastinum and neck, including therefore the kidneys, adrenals, pancreas, spleen, liver, heart, great vessels, thymus, trachea, œsophagus and any abnormal formations related to them. When insufflation is combined with tomography in the appropriate planes, these organs may be demonstrated with remarkable clarity. In some cases, alternative radiological methods are available which insufflation is not likely to supplant (angiography, barium swallow, etc.), but even here, a combination of both measures may prove advantageous on occasion, by reason of the indication which insufflation can give of the state of the surrounding areolar planes. Some of the possibilities of the method are illustrated in the accompanying radiographs.

\section{Determination of Attachment or Fixity}

Conventional methods afford no ready way of gauging the degree of attachment or fixity of structures which normally are neither palpable nor possessed of physiological mobility. Figures I-3 show examples of the way in which pneumography can provide evidence on this point.

Fig. I illustrates a very bulky tumour of the right kidney. No gas has penetrated within the capsule indicating extensive infiltration of that structure, but the perinephric space fills on every side, indicating the absence of fixation to neighbouring structures. In spite of its size, the mass was removed with ease.

Fig. 2a shows a cancer of the cardiac end of the stomach outlined by barium. In Fig. $2 b$, gas is seen to pass freely round the fundus of the stomach and subphrenic regions and to enter the lower part of the mediastinum. This tumour was free from local spread and was resected without difficulty. In Fig. 2c, on the other hand, a pneumogram of a growth apparently similar in the barium meal, gas fails completely to appear in the left hypochondrium and at operation the growth was found to be fixed by extensive local spread. At the present time, in the surgical clinic of the University of Padua, all patients with gastric cancers are investigated in this way and those in whom it is impossible to induce gas to surround the tumour and enter the mediastinum are not explored, unless the need for a palliative procedure makes operation necessary.

Similar information is available in respect of intra-thoracic lesions. Fig. 3 a shows a large spherical mass in the right lower pulmonary lobe. The relation of this to the mediastinum is not clear. Mediastinal pneumography, however (Fig. 3b), shows that the mass is quite separate and that the mediastinum is freely permeable by the gas. At operation, the lesion proved to be an echinococcal cyst.

The same principle applies in all parts of the body; adherence of pelvic tumours to the bony pelvis and local infiltration around the growths of the œsophagus and pancreas have also been demonstrated in the same way.

\section{Delineation of Soft Structures otherwise Difficult} to Visualize

The attempt to outline a suprarenal suspected to be the site of tumour formation is perhaps at present the most usual occasion for pneumography. The procedure is by now familiar enough to require little further comment beyond stressing the great value of performing tomography, by means of which it is often possible to obtain sharis outlines of both adrenals (though not usually on the same film), even when the normal antero-posterior pneumogram fails to show them. Pneumography also offers a possible method of studying the gross morphology of the glands in any other condition thought to be associated with adrenal hyperplasia. For example, there is now a considerable literature implicating the adrenals in Buerger's disease, and pneumography may show them to be hyperplastic (Pettinari and Castiglioni, 1959).

Fig. 4a illustrates a right congenital hypoplastic kidney and Fig. $4 \mathrm{~b}$ its normal fellow, both outlined by gas. The right nephrectomy specimen subsequently obtained is seen in Fig. 4c. If the hypoplastic kidney does not opacify on aortography and technical difficulty prevents catheterization of the ureter, pneumography may offer the only means of distinguishing between hypoplasia and true agenesis.

Figs. 5 to 8 show some less familiar pneumographic appearances. In Fig. 5 a, a rounded mass is seen adjacent to the aortic arch. After induction of pneumomediastinum (Fig. $5 \mathrm{~b}$ ), an oblique view in the plane of the arch shows the mass to be well surrounded by gas except on one side where it is attached to the aorta by a narrow stalk. This attachment was thought to be too limited to 


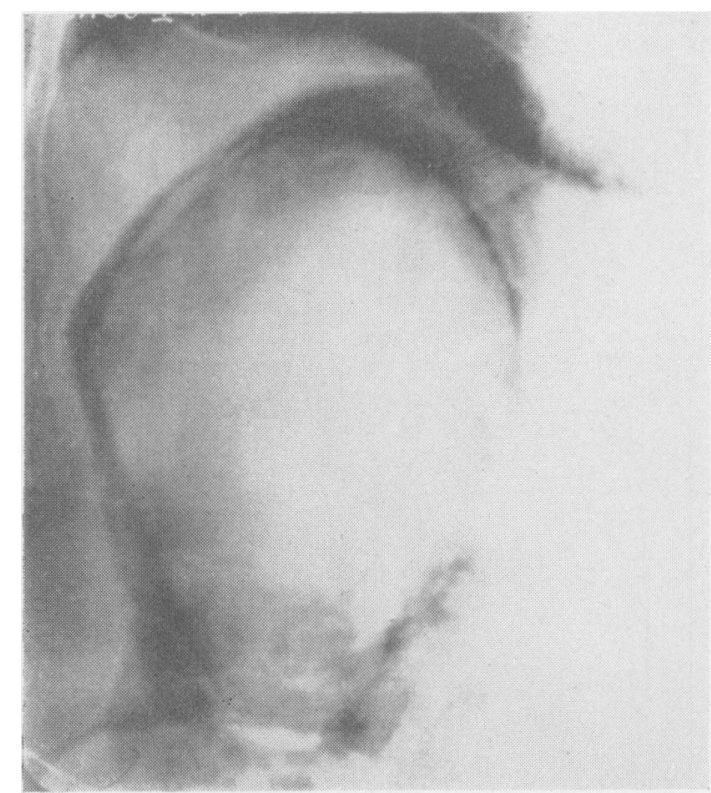

FIG. 1.-Bulky tumour of right kidney, free on all sides (pneumogram).

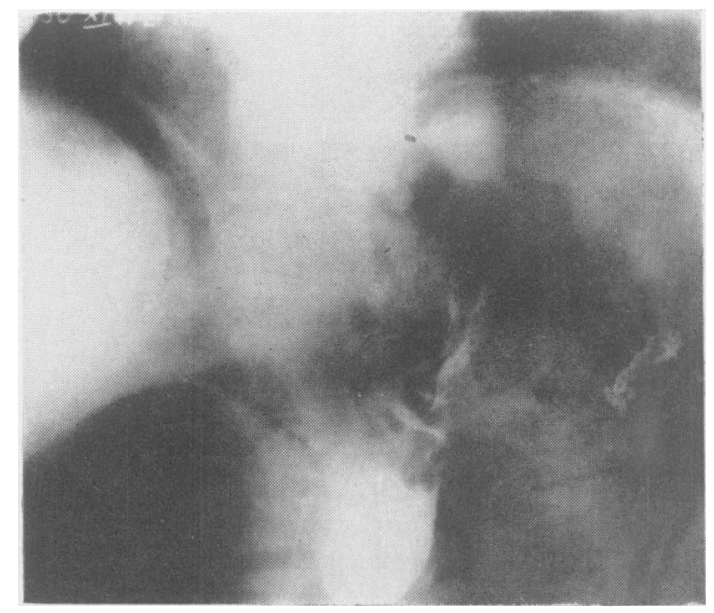

FIG. 2.-(b) Pneumogram of growth in Fig. 2(a); air surrounds the growth.
Fig. 2.-Carcinoma of gastric fundus, without extragastric spread.

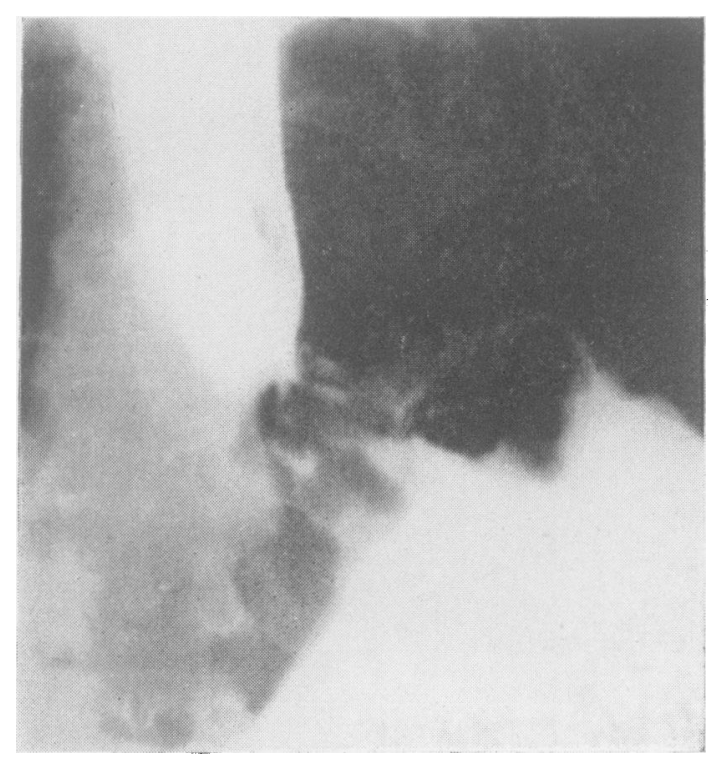

FIG. 2.-(a) Barium meal.

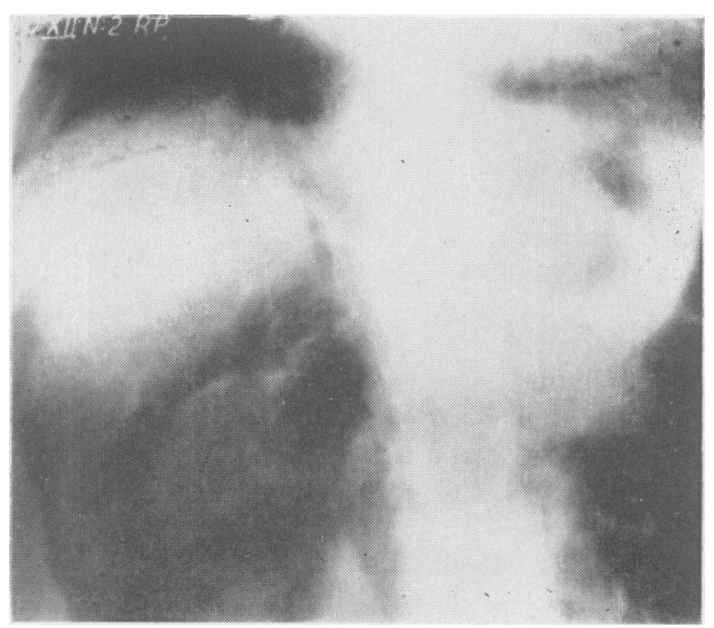

Frg. 2.-(c) Pneumogram of similar growth; no air surrounds it. 

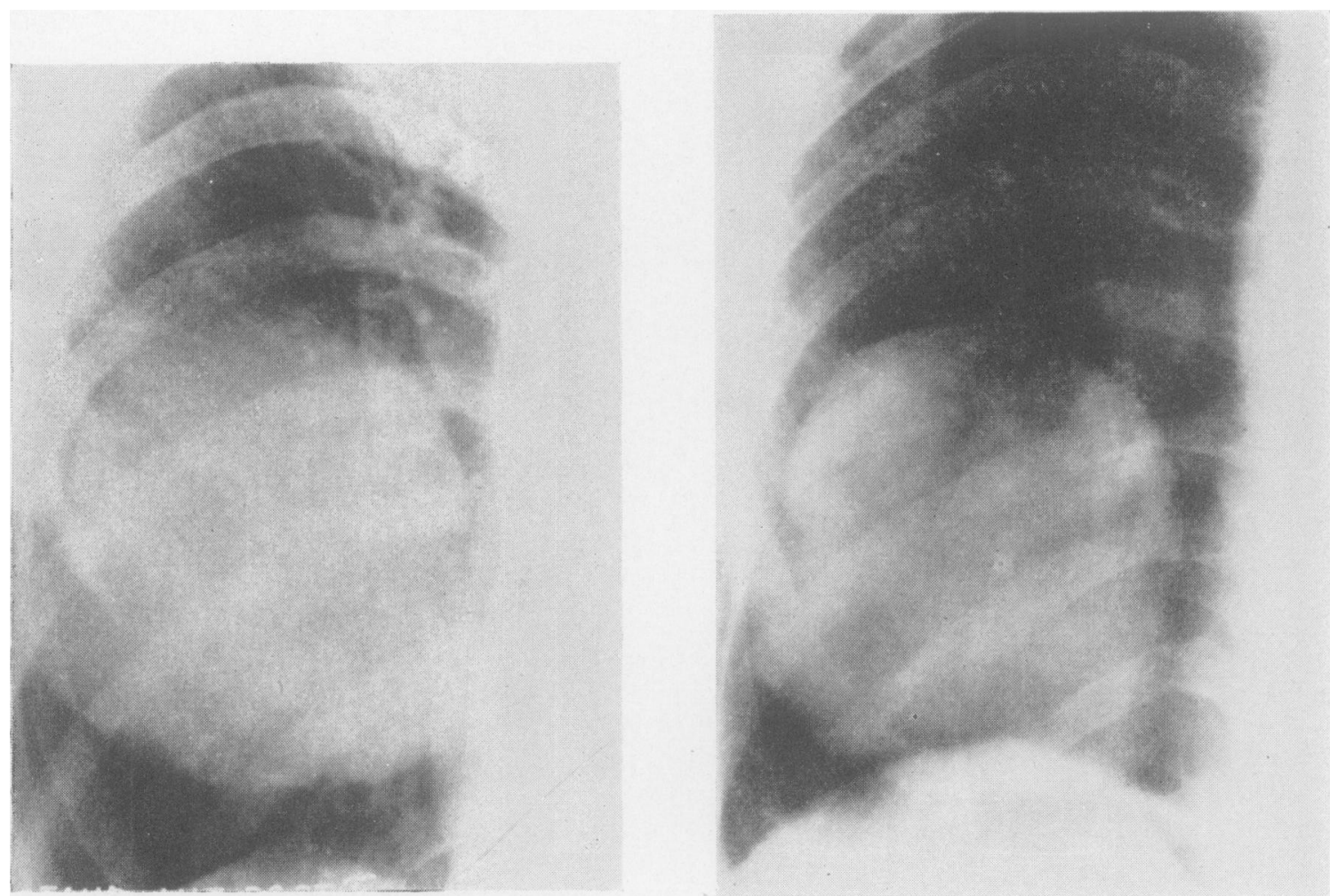

FIG. 3. - Right lower lobar pulmonary mass.

(a) Plain film.

(b) Pneumogram showing separation from a norma? mediastinum (echinococcal cyst).

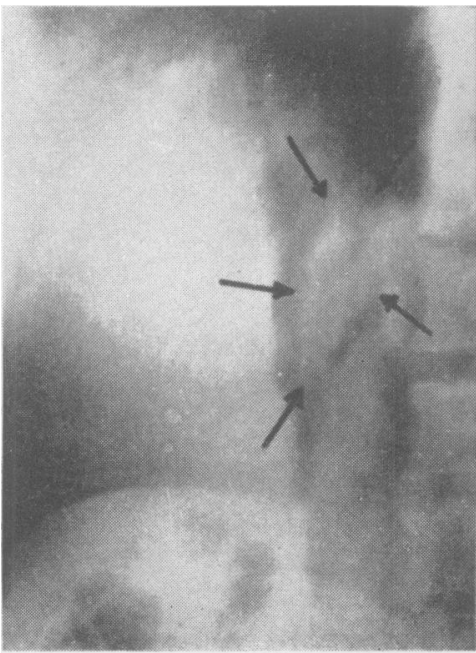

(a)

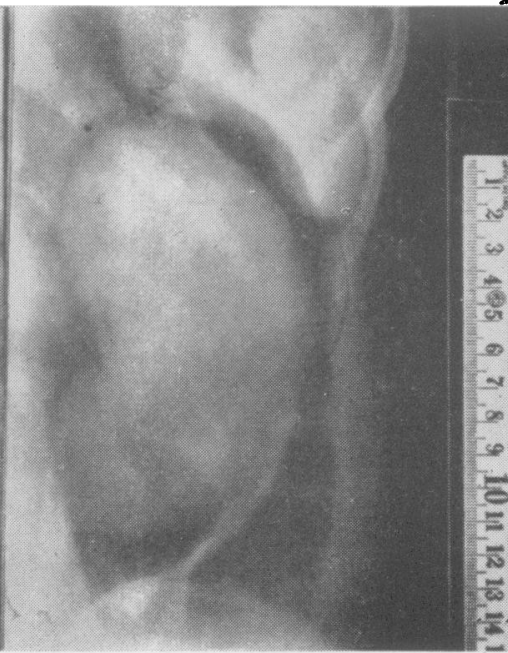

(b)

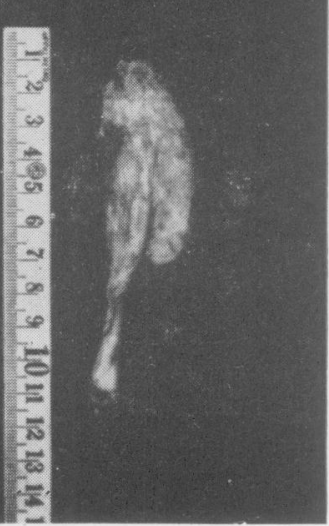

(c)

FIG. 4.-(a) Hypoplastic right kidncy. (b) Normal left kidney (pneumograms). (c) Right kidney, operative specimen. 

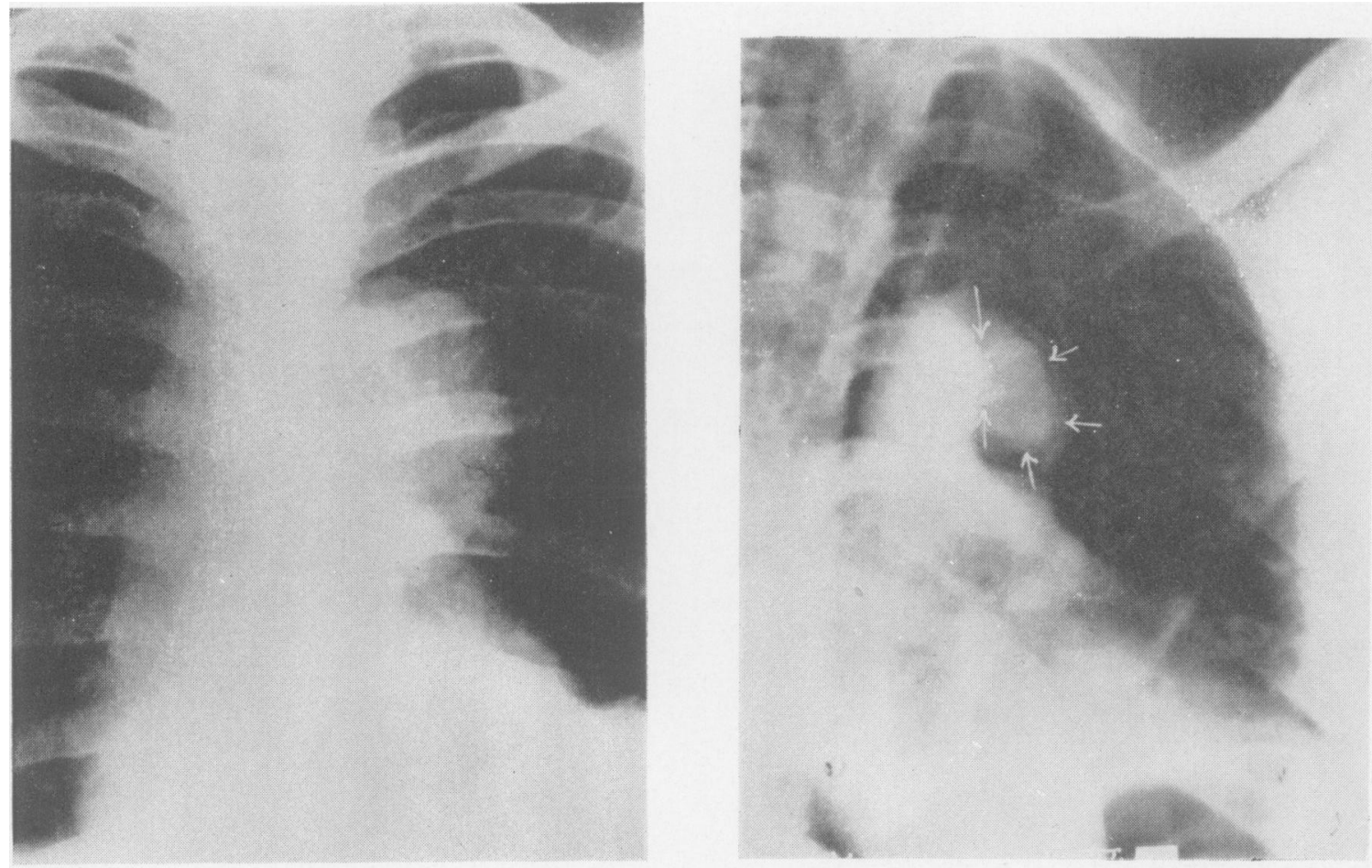

FIG. 5. - Fibroma on ascending arch of aorta.

(a) Plain film

(b) Pneumogram.

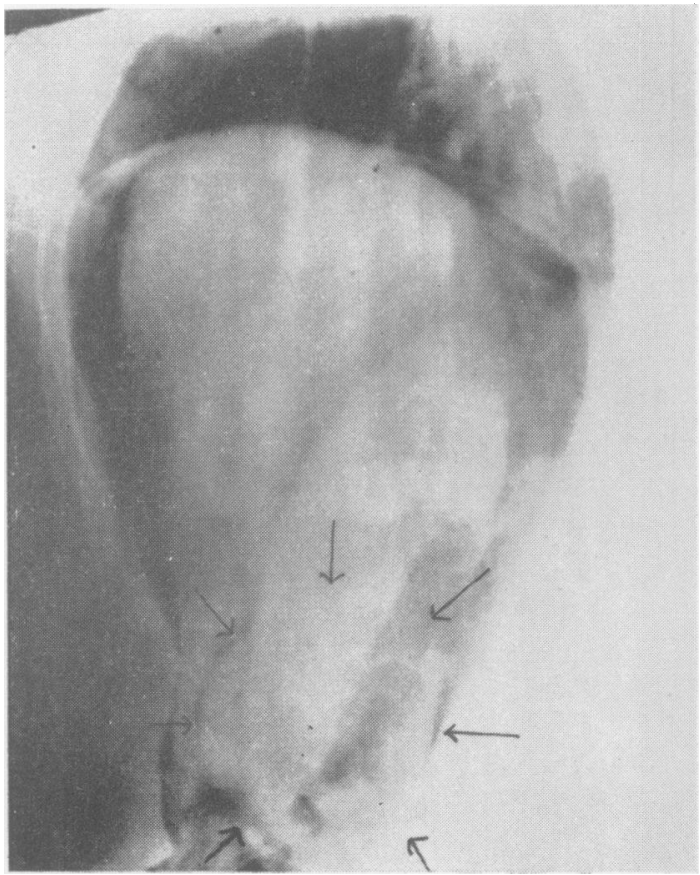

Fig. 7.-Small lower polar renal carcinoma (pneumogram).

Fig. 6.-Thymus gland (pneumogram).

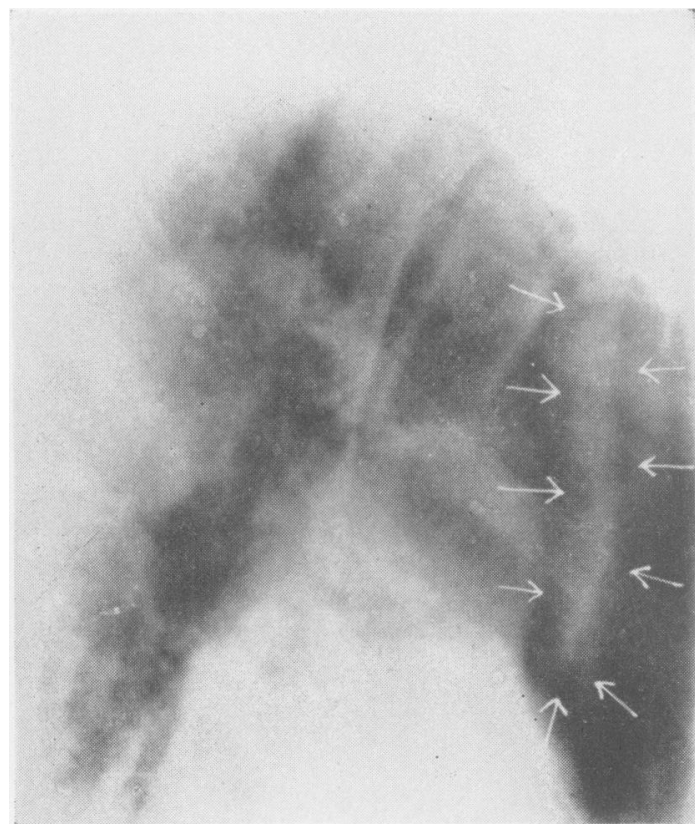



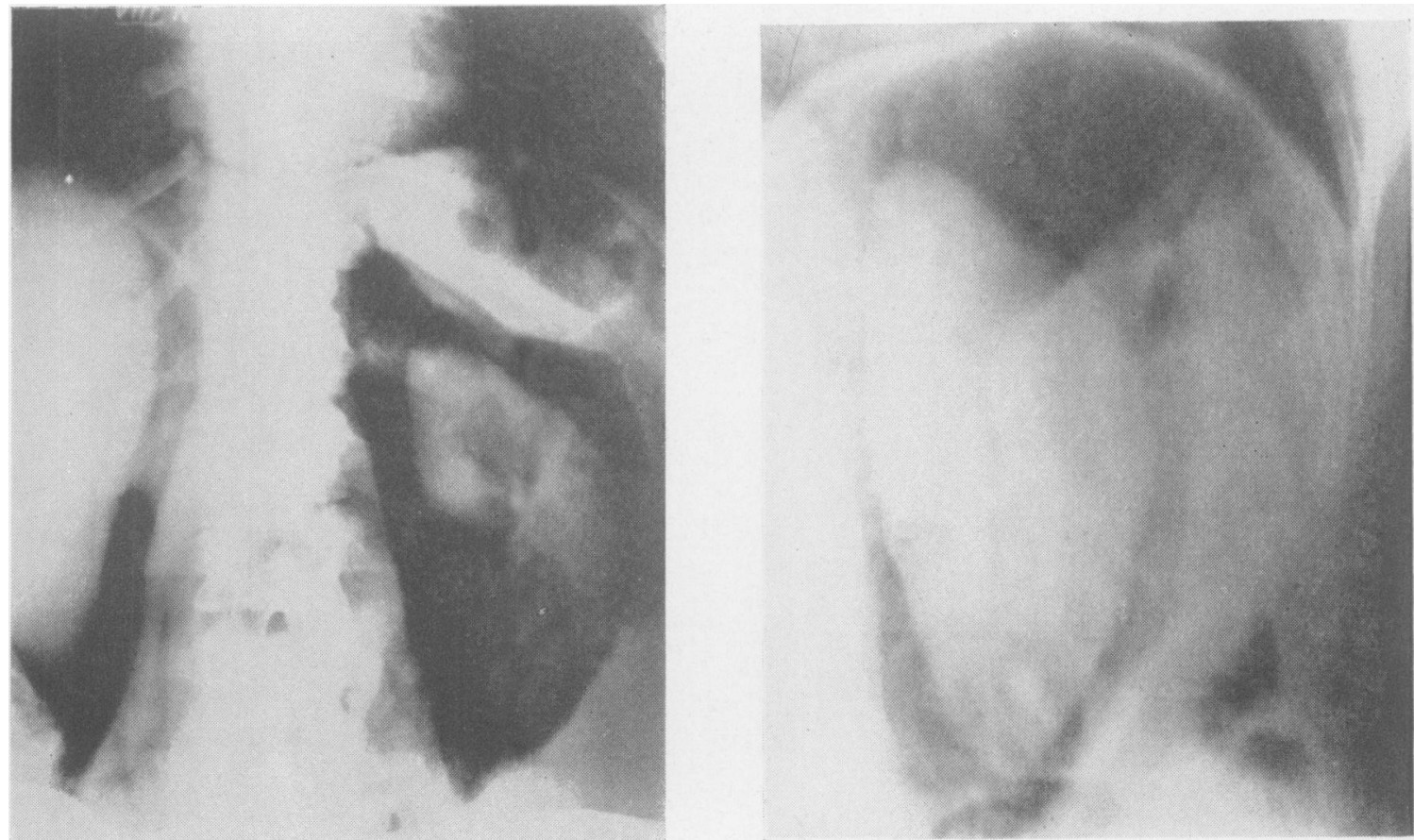

(a)

FIG. 8. - Intermittent torsion of spleen (pneumogram). (a) Normal position. (b) Spleen rotated downwards and laterall: $\vec{\theta}$

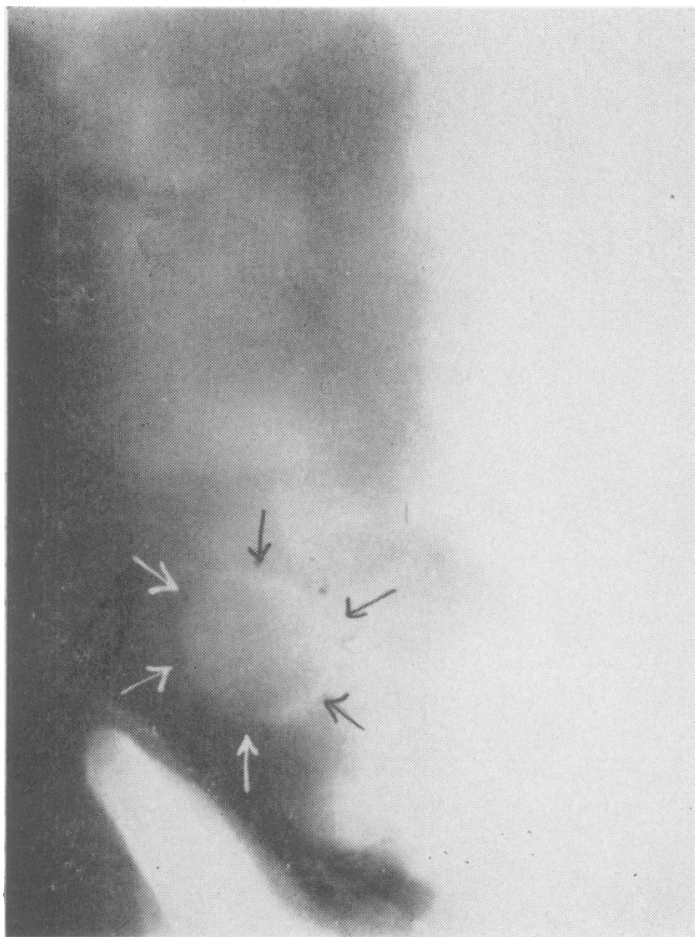

FIG. 9.-Congenital cyst of right hepatic lobe (pneumogram)

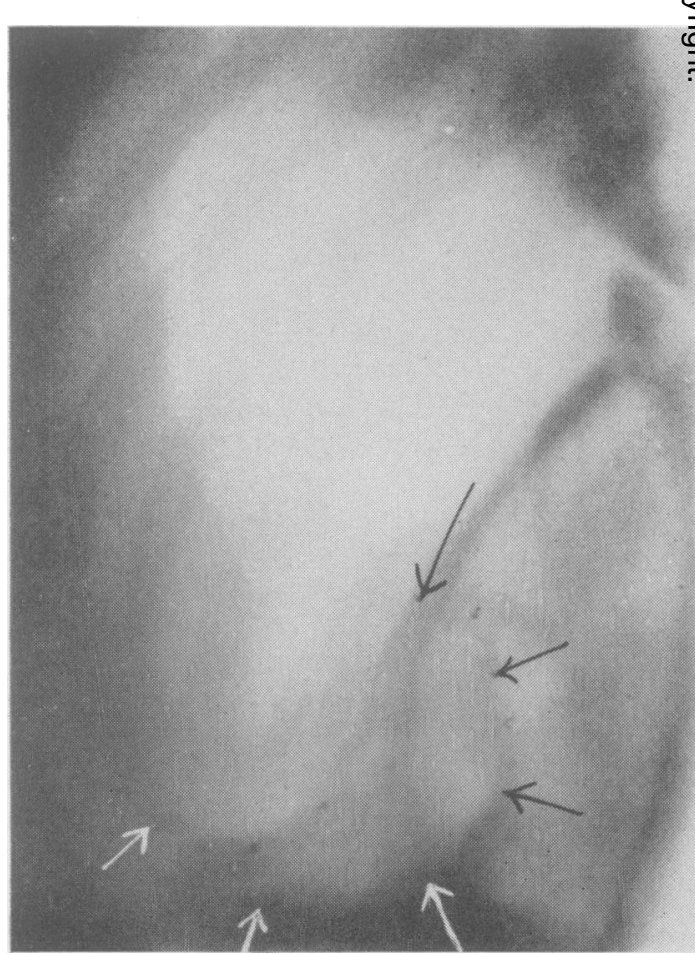

FIG. 10.-Benign adenoma of right hepatic lobe (pneumogram). 
suggest malignancy. At operation, it proved to be a fibroma arising from the tunica adventitia of the aorta.

Fig. 6 shows the clarity with which the thymus may be outlined in lateral view in the presence of a pneumomediastinum. This example is considered to show hypertrophy. Alajouanine, Bariety, Castaigne and Coury (1957), who investigated ten cases of myasthenia gravis in which routine radiography (including tomography) had proved negative, were able with the aid of pneumography to demonstrate thymic hypertrophy in eight. In six of these, the hypertrophy was later confirmed at operation. Of the two cases with apparently normal thymus glands, one later came to postmortem and the result of the pneumograms was confirmed.

Fig. 7 shows the outline of a small lower polar renal carcinoma, free from local attachment. Several cases have been seen in which the investigation of symptomless hæmaturia has yielded normal pyelograms, while pneumography has revealed a small peripheral tumour similar to this one. The same experience is also recorded and illustrated by Tinckler (1953). In any case with normal pyelograms in which the hæmaturia is really believed to be renal in origin, but remains unexplained, pneumography is the next logical step.

It is usually easy enough to diagnose horse-shoe kidney by conventional methods, but if operation on one side is called for, information is needed about the configuration of the parenchyma and especially the form and position of the isthmus. Providing both sides have normal circulation, aortography can give this information but it can be more readily obtained by pneumography. Aortography is also not without danger and requires much more highly specialized facilities.

In Fig. 8, are shown two films of a patient suffering from intermittent bouts of severe, left hypochondriac pain. Fig. 8a, taken in a symptomfree interval, shows normal pneumographic appearances. The left kidney and spleen are recognizable, separated by an air-containing gap. The spleen, which is seen almost end-on in this projection, occupies a small space under the highest part of the cupola of the diaphrogm. In Fig. 8b, taken a few days later during a bout of pain, the appearance of the spleen has completely changed. It is now seen broadside-on and has vacated its previous site under the diaphragm, to extend down the flank, overlying the kidney shadow. A preoperative diagnosis of intermittent torsion of the pedicle of a mobile spleen was made, and this proved to be correct.

In the University Surgical Clinic, Padua, pneumography is regularly performed along with aortography, splenoportography, and hepatic vein phlebography in the investigation of hepatic and hepato-splenic disease. It reveals not only the volume, but also the contours, relations and attachments of both organs. In some conditions, the findings are very characteristic; congenital anomalies, tumours and cysts of the liver are usually recognized with ease. Fig. 9 shows a cyst of the anterior margin of the right lobe in a congenitally polycystic liver, while Fig. Io shows a benign adenoma similarly situated. In hepatic carcinoma, evidence of infiltration and fixity or their absence may also be obtained according to the criteria outlined above in connection with other organs.

\section{Summary}

I. A series of over 2,000 pre-sacral oxygen insufflations without complication is recorded.

2. Gas so introduced can be induced to pass to all parts of the deep areolar tissue planes of the trunk. Either alone, or combined with tomography and the simultaneous use of opaque contrast media, this method can give useful indications of the degree and location of fixity in neoplastic and inflammatory conditions. It can also outline soft-tissue structures which may not be visualized by other means.

\section{Acknowledgments}

I should like to acknowledge help and advice on numerous matters of detail from Prof. $M$. Baccaglini. The illustrations are derived from the records of patients treated personally by Prof. V. Pettinari.

\section{REFERENCES}

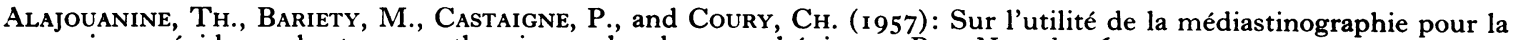
mise en évidence des tumeurs thymiques chez les myasthéniques, Rev. Neurol., 96, 3.

Baccaglini, M. (1948a): Visualizzazione degli spazi retroperitoneali del cane mediante iniezione di gas.

(1948b): Visualizzazione degli spazi retroperitoneali del cane mediante gas.

(r949): Title unknown.

- (1950): Rilievi di tecnica sul retropneumoperitoneo con particolare riguardo alla possibilità di ottenere il pneumomediastino.

(The above four references cited by Bonomini and Baccaglini, 1953.)

Blackwood, J. (195 I): Presacral Perirenal Pneumography, Brit. J. Surg., 39, 1 I I.

Bonomini, B., and Baccaglini, M. (1953): 'Pneumoretroperitoneo e Pneumomediastino: L'enfisema diagnostico dei tessuti areolari profondi del tronco', Bologna, Capelli. 
Carelli, H. H. (rg2 ra): Sur le pneumopéritoine et sur une méthode personelle pour voir le rein sans pneumopéritoine, Bull. Soc. méd. Hôp. Paris, 45, 1409.

- (192 rb): Demonstration von Bildern zur röntgengraphischen Darstellung der Niere, Berl. klin. Wschr., 58, r 509.

*___ and Sordelli, A. (1921): Un nuevo procedimiento para explorar al rinón, Rev. Asoc. méd. argent., 34, 424.

Ciarla, E. (r94ra): Grandi iniezioni peridurali ed epidurali di ossigeno e di aria come nuovo metodo di esplorazione radiologica, applicazioni terapeutiche, Radiol. med., 28, 247.

- (194Ib): Nuovo metodo di esplorazione radiologica per mezzo di grandi iniezioni peridurali di aria, effetti terapeutici dell'aria iniettata, Forze sanit. (Cited by Bonomini and Baccaglini, 1953; page number not given.)

Davidson, J. K., Havard, C. W. H., and Bodley-Scot r, R. (1959): Radiological Demonstration of Enlarged Retroperitoneal Lymph Nodes, Lancet, i, roo8.

Harkins, H. N., and Harmon, P. H. (1934): Embolism by Air and Oxygen: Comparative Studies, Proc. Soc. exp. Biol. Med., 32, 178.

Landes, R. R., and Ransom, C. L. (1957): Technique for Use of Carbon Dioxide in Presacral Retroperitoneal Pneumography, Surg. Gynec. Obstet., 105, 268.

Pettinari, V. (I955): Moderni mezzi d'indagine nei tumori maligni del fegato, Chir. Pat. sper., 3, I.

†—, and BACCAGlini, M. (I95I): El neumomediastino: tecnica y resultados, Sci. med. ital., $2,25 \mathrm{I}$.

-, and CASTIglioni, G. C. (1959): La chirurgia delle ghiandole surrenali, Minerva chir., r4, 581 .

Ransom, C. L., Landes, R. R., and McLelland, R. (1956): Air Embolism following Retroperitoneal Pneumography, a Nation-wide Survey, f. Urol., 76, 664.

Rosenstein, P. (1921): Die Pneumoradiographie des Nierenlagers, ein neues Verfahren zur radiographischen Darstellung der Nieren und ihrer Nachbarorgane (Nebenniere, Milz, Leber), Zschr. Urol., I5, 447.

Ruiz Rivas, M. (1947): Neuva tecnica del neumorinon, Rev. clin. espan., 25, 206.

(1948): Diagnostica Radiologica: el neumorinon, tecnica original, Arch. espan. urol., 4, 228.

- (1950): Roentgenological Diagnosis: Generalised Subserous Emphysema through Single Puncture, Amer. $\mathcal{Y}$. Roentgenol., 64, 723.

Tinckler, L. F. (I953): Presacral Perirenal Pneumography, F. Fac. Radiol. Lond., 4, 268.

Zinsser, H. H. (I 954): Retroperitoneal Insufflation, A.M.A. Arch. Surg., 69, 736.

* This reference, commonly cited, appears in ' Garrison and Morton's Medical Bibliography', by Morton, L. T., Grafton \& Co., London, and edition, 1954. According to the 'British Union-Catalozue of Periodicals' (Ed. Stewart, Hammond and Saenger), Vol. 4, I955-58, Bu tterworth, London, the text is not inc'uded in any library in the United Kingdom, but the two previous references (Carelli, I92 Ia and b) confir.n worth, London, the text is not inciucted
its existence and indicate its content.

$\uparrow$ This pe:iodical appears in English, German, Italian and Spanish. The page number refers to the Spanish edition. 